\title{
Assessment of a Fully Optimized DPX-Based Procedure for the Multiclass Determination of Pesticides in Drinking Water Using High-Performance Liquid Chromatography with Diode Array Detection
}

\author{
Gabriela Corazza, ${ }^{a}$ Josias Merib, ${ }^{b}$ Sângela N. do Carmo, ${ }^{a}$ Leila D. Mendes ${ }^{a}$ and \\ Eduardo Carasek ${ }^{\circledR} * a$ \\ ${ }^{a}$ Departamento de Química, Universidade Federal de Santa Catarina, \\ 88040-900 Florianópolis-SC, Brazil \\ ${ }^{b}$ Departamento de Farmacociências, Universidade Federal de Ciências da Saúde de Porto Alegre, \\ 90050-170 Porto Alegre-RS, Brazil
}

\begin{abstract}
In this study, a disposable pipette extraction (DPX)-based procedure was fully optimized for the multiclass determination of 12 pesticides, with significant differences in their physicochemical properties, using high-performance liquid chromatography coupled with diode array detection (HPLC-DAD). The variables optimized were type of extraction phase, sample $\mathrm{pH}$, sample volume, number of extraction and desorption cycles, time of each cycle, type and volume of desorption solvent, and $\mathrm{NaCl}$ concentration of the samples. The analytical parameters of merit were determined under optimized conditions and satisfactory results were achieved, with limits of detection (LOQs) varying from $0.06 \mu \mathrm{g} \mathrm{L}^{-1}$ for carbofuran to $2.30 \mu \mathrm{g} \mathrm{L}-1$ for carbendazim and correlation coefficients of 0.9923 to 0.9999 . Relative recoveries ranged from 75 to $117 \%$. Good results were achieved for intraday $(\mathrm{n}=3)$ precision $(1$ to $20 \%)$ and interday $(\mathrm{n}=9)$ precision $(1$ to $24 \%)$. The method was applied to the monitoring of 20 drinking water samples collected from water treatment plants.
\end{abstract}

Keywords: disposable pipette extraction, high-performance liquid chromatography, pesticides, water analysis, multiclass determination

\section{Introduction}

Pesticides are intensively used in agriculture for the control of a variety of pests, including weeds and insects, in order to increase the productivity. However, the inappropriate use of these compounds causes contamination of surface water, ground water and soil, consequently damaging the ecosystems and human health. ${ }^{1,2}$ Brazil is one of the largest consumers of pesticides in the world, which results from shortcomings with regard to implementing public policies and the use of pesticides that have not been registered in Brazil (i.e., product smuggling). ${ }^{3}$

Thus, in this context, the monitoring of natural water supplies is an issue of great importance. The Brazilian government has set tolerance levels for pesticides in drinking water using maximum concentration levels (MCLs), which are in the range of parts-per-billion $\left(\mu \mathrm{g} \mathrm{L}^{-1}\right){ }^{4}$ Due to the low levels of the permitted concentrations, the use of analytical

\footnotetext{
*e-mail: eduardo.carasek@ufsc.br
}

instruments with high selectivity and detectability, such as gas chromatography-mass spectrometry (GC-MS), ${ }^{5}$ liquid chromatography-tandem mass spectrometry (LC-MS/ MS), ${ }^{6}$ ultra-high-performance liquid chromatographytandem mass spectrometry (UHPLC-MS/MS), ${ }^{7}$ is often necessary to determine these compounds. However, instrumentation based on MS detectors is expensive and is not available in some laboratories. An alternative is the use of approaches associated with lower costs, such as highperformance liquid chromatography coupled with diode array detection (HPLC-DAD), together with an effective sample preparation technique aimed at concentrating the analytes, reducing possible interfering compounds, and allowing for the transfer of the analytes to an extraction phase compatible with the analytical instrument.

Some of the most commonly used extraction and microextraction techniques reported for the determination of pesticides in aqueous samples are based on solid-phase extraction (SPE) ${ }^{6,8}$ solid-phase microextraction (SPME), ${ }^{9}$ dispersive liquid-liquid microextraction (DLLME), ${ }^{10}$ 
single-drop microextraction $(\mathrm{SDME})^{11}$ and rotating disk sorptive extraction (RDSE). ${ }^{7}$ In addition, analytical methodologies based on the quick, easy, cheap, effective, rugged and safe (QuEChERS) method have been widely used for multi-residue analysis and are recommended in official methods. ${ }^{12}$

A promising technique, developed in 2003 and based on the principles of SPE, is disposable pipette extraction (DPX) ${ }^{13}$ This technique consists of a pipette containing an extraction phase (sorbent) dispersed between two filters. The extraction procedure employs the following steps: (i) conditioning to activate the sorbent sites; (ii) sample aspiration; (iii) air aspiration to allow a dynamic mixture between the sorbent and the sample; (iv) sample discard; (v) aspiration and discard of solvent to remove possible interfering compounds; and ( $v i$ ) solvent aspiration followed by air aspiration for the liquid desorption of the analytes. The aspiration of air allows for a dynamic mixture of the sample with the sorbent phase, leading to rapid sorption equilibrium between the analyte and the sorbent. Therefore, the advantages of using DPX include rapid extraction along with the use of a small mass of the sorbent phase and low volumes of organic solvent and sample, thus adhering to green chemistry principles. In addition, DPX-based approaches generally exhibit lower analysis cost compared with SPE..$^{14,15}$

The aim of this study was to develop a reliable, environmentally friendly and low-cost DPX-based analytical method for the multiclass determination of 12 pesticides with different physicochemical properties. The method proposed was fully optimized and validated in-house using HPLC-DAD. The method developed was applied to the monitoring of the analytes in 20 drinking water samples (after the treatment process) collected from water treatment plants located in 13 cities of Santa Catarina State, Brazil. This strategy was adopted to evaluate the drinking water quality based on the current Brazilian regulation. ${ }^{4}$

\section{Experimental}

\section{Reagents and standard solutions}

Solid standards of carbendazim, simazine, carbofuran, atrazine, diuron, 2,4-dichlorophenoxy acetic acid (2,4-D), 2,4,5-trichlorophenoxy acetic acid (2,4,5-T), tebuconazole, parathion-methyl, metolachlor, dichlorodiphenyldichloroethane $(4,4$ '-DDD) and dichlorodiphenyldichloroethylene (4,4'-DDE) were obtained from Sigma-Aldrich (Milwaukee, WI, USA). Individual stock solutions at a concentration of $10 \mathrm{~g} \mathrm{~L}^{-1}$ (carbofuran, diuron, 2,4-D, 2,4,5-T and tebuconazole), $4 \mathrm{~g} \mathrm{~L}^{-1}$ (parathion-methyl and metolachlor), $1 \mathrm{~g} \mathrm{~L}^{-1}$ (4,4'-DDD and 4,4'-DDE), $500 \mathrm{mg} \mathrm{L}^{-1}$ (atrazine), $400 \mathrm{mg} \mathrm{L}^{-1}$ (carbendazim) and $250 \mathrm{mg} \mathrm{L}^{-1}$ (simazine) were prepared in methanol ( $\left.\mathrm{MeOH}\right)$. Working solutions containing a mix of the analytes, each at a concentration of $50 \mathrm{mg} \mathrm{L}^{-1}$ in $\mathrm{MeOH}$, were prepared by appropriate dilution of the stock solution. The chemical structure of each analyte and some of the physicochemical properties are listed in Table 1. ${ }^{16}$

Acetonitrile (ACN), $\mathrm{MeOH}$ and acetone (HPLC grade) were purchased from J.T. Baker (Mallinkrodt; Bedminster, $\mathrm{NJ}$, USA). Ultrapure water $(18.2 \mathrm{M} \Omega \mathrm{cm})$ was obtained from a Mega Purity system (Billerica, MA, USA), and hydrochloric acid and sodium chloride were obtained from Vetec (Rio de Janeiro, Brazil). DPX-reversed phase (DPX-RP) and DPX-weak anion exchange (DPX-WAX)

Table 1. Chemical structures and some physicochemical properties of the pesticides under study ${ }^{16}$

Simazine


Table 1. Chemical structures and some physicochemical properties of the pesticides under study ${ }^{16}$ (cont.)

\begin{tabular}{|c|c|c|c|}
\hline Analyte & Chemical structure & $\mathrm{p} K_{\mathrm{a}}$ & $\log \mathrm{K}_{\mathrm{ow}}$ \\
\hline Atrazine & & 4.60 & 3.12 \\
\hline Diuron & & 13.55 & 2.68 \\
\hline 2,4-D & & 2.98 & 2.43 \\
\hline $2,4,5-\mathrm{T}$ & & 2.88 & 3.10 \\
\hline Tebuconazole & & - & 3.70 \\
\hline Parathion-methyl & & - & 2.82 \\
\hline Metolachlor & & - & 3.03 \\
\hline 4,4'-DDD & & - & 5.82 \\
\hline 4,4'-DDE & & - & 6.96 \\
\hline
\end{tabular}

pKa: logarithmic acid dissociation constant; Kow: octanol-water partition coefficient; 2,4-D: 2,4-dichlorophenoxy acetic acid; 2,4,5-T: 2,4,5-trichlorophenoxy acetic acid; 4,4'-DDD: dichlorodiphenyldichloroethane; 4,4'-DDE: dichlorodiphenyldichloroethylene.

(pipette tips of $1 \mathrm{~mL}$ with $20 \mathrm{mg}$ of sorbent phase) and DPX-blank (pipette tips of $1 \mathrm{~mL}$ without sorbent phase) were acquired from DPX Labs (Columbia, SC, USA). The sorbent phase $\mathrm{C} 18$ was obtained from SPE cartridges (Phenomenex; Torrance, CA, USA).

\section{HPLC-DAD analysis}

A Shimadzu Prominence LC 20AT series HPLC system (Kyoto, Japan) equipped with a diode array detector (RF 20A series) was used in this study. Chromatographic 
separations were carried out using a Phenomenex Gemini-NX C18 column $\left(5.0 \mu \mathrm{m}, 4.6 \times 250 \mathrm{~mm}^{2}\right)$. The injection volume was $20 \mu \mathrm{L}$ at a flow rate of $1 \mathrm{~mL} \mathrm{~min}^{-1}$ of the mobile phase in gradient mode. In the gradient method, the mobile phase was initially comprised of $90 \%$ A (ultrapure water containing $1 \% \mathrm{v} / \mathrm{v}$ of phosphoric acid) and $10 \% \mathrm{~B}(\mathrm{ACN})$. The content of $\mathrm{B}$ was then increased from 10 to $30 \%$ for 3 up to $7 \mathrm{~min}$. The B content was further increased from 30 to $70 \%$ for 7 up to $35 \mathrm{~min}$, and then from 70 to $90 \%$ from 35 up to $36 \mathrm{~min}$. This condition was maintained up to $50 \mathrm{~min}$, when the initial condition was returned and kept for $10 \mathrm{~min}$ for conditioning of the column. All analytes were detected at a wavelength of $200 \mathrm{~nm}$ and the chromatographic data were analyzed with LC Solution software (Shimadzu; Kyoto, Japan).

\section{Optimization of DPX procedure}

The DPX procedure was fully optimized using multi and univariate approaches in order to obtain the best extraction conditions. Statistica $8.0^{17}$ was used for the data treatment in multivariate approaches. Extractions were performed using ultrapure water spiked with $100 \mu \mathrm{g} \mathrm{L} \mathrm{L}^{-1}$ of each analyte. Firstly, the type of sorbent phase was evaluated. In this step, the sorbent phases evaluated included a DPX-WAX and DPX-RP. DPX-WAX was performed with tips containing $20 \mathrm{mg}$ of sorbent phase comprised of poly-amino groups and DPX-RP was carried out with tips containing $20 \mathrm{mg}$ of styrene-divinylbenzene. Another sorbent phase evaluated was obtained from SPE cartridges (C18). In this case, a mass of $20 \mathrm{mg}$ of $\mathrm{C} 18$ was inserted into DPX blank tips corresponding to DPX-C18. Due to the different $\mathrm{p} K_{\mathrm{a}}$ values of the analytes, the sample $\mathrm{pH}$ was evaluated (at $\mathrm{pH} 2,4,6,8,10$ and 12) using a univariate approach. After these initial optimization steps, a comparison of the extraction efficiency obtained with the sorbent phases evaluated using the normalized chromatographic peak areas was performed.

The best solvent for the desorption of the analytes was evaluated using a simplex-lattice design. In this case, ACN, $\mathrm{MeOH}$ and acetone were used to build a response surface. Relevant parameters in the extraction and desorption steps were optimized. For the extraction step, the sample volume (165 to $835 \mu \mathrm{L}$ ), number of extraction cycles (1 to 11 ) and time of each cycle (5 to $55 \mathrm{~s}$ ) were optimized through a central composite design. For the desorption step, the volume of desorption solvent ( 80 to $420 \mu \mathrm{L}$ ), number of desorption cycles (1 to 11 ) and time of each cycle (5 to $55 \mathrm{~s}$ ), were also optimized through a central composite design. In the last optimization step, the $\mathrm{NaCl}$ concentration added to the sample was studied using a univariate approach.

\section{Characterization of sorbent phase}

The sorbent phase that exhibited the best results for the extraction of the analytes was characterized by Fourier transform infrared spectroscopy (FTIR), using a Varian 3100 spectrometer (Santa Clara, CA, USA). The FTIR spectra were generated from $\mathrm{KBr}$ pellets. In addition, the morphology of the material was assessed through micrographs obtained by scanning electron microscopy (SEM), using a Hitachi TM 3030 microscope (Tokyo, Japan).

\section{Analytical figures of merit and analysis of real samples}

Calibration curves were obtained using tap water samples spiked with carbendazim at concentrations from 50 to $600 \mu \mathrm{g} \mathrm{L}^{-1}$, simazine and diuron from 1 to $200 \mu \mathrm{g} \mathrm{L} \mathrm{L}^{-1}$ and the other pesticides from 5 to $200 \mu \mathrm{g} \mathrm{L}^{-1}$. The extractions were performed in triplicate using DPX-WAX. Correlation coefficients ( $r$ ) were calculated based on the calibration curves. The linearity of the calibration curves was verified using analysis of variance (ANOVA). The values for the limit of detection (LOD) and limit of quantification (LOQ) were calculated based on signal-to-noise ratios of 3 and 10 , respectively. Accuracy and precision were assessed by performing extractions in tap water samples spiked with the analytes at three different concentrations: carbendazim (50, 200 and $\left.600 \mu \mathrm{g} \mathrm{L}^{-1}\right)$, simazine and diuron (1, 50 and $\left.200 \mu \mathrm{g} \mathrm{L}^{-1}\right)$ and other pesticides (5, 50 and $\left.200 \mu \mathrm{g} \mathrm{L}^{-1}\right)$, in triplicate. Accuracy was evaluated as the percentage of relative recovery and intraday $(n=3)$ and interday $(n=9)$ precision assays were performed in three concentrations and calculated based on the relative standard deviation (RSD). In addition, the Youden test was performed to evaluate the robustness of the method and the results used to obtain Daniel and Lenth graphs generated in Start Action software. ${ }^{18}$

Twenty samples of water collected from the output of water treatment plants located in 13 cities of Santa Catarina State, Brazil, were analyzed. Some cities have more than one water treatment plant and, in these cases, additional samples were obtained. The map in Figure 1a shows the location of Santa Catarina State in Brazil, and the cities in which the samples were collected can be seen in Figure $1 \mathrm{~b}$. The sampling was carried out in partnership with the Sanitary Surveillance of Santa Catarina State (Vigilância Sanitária do Estado de Santa Catarina) and samples were collected in amber glass bottles, stored at $4{ }^{\circ} \mathrm{C}$ and analyzed within three days. The strategy of collecting samples after the treatment process was adopted in order to evaluate the quality of water, which is effectively provided to the population. 


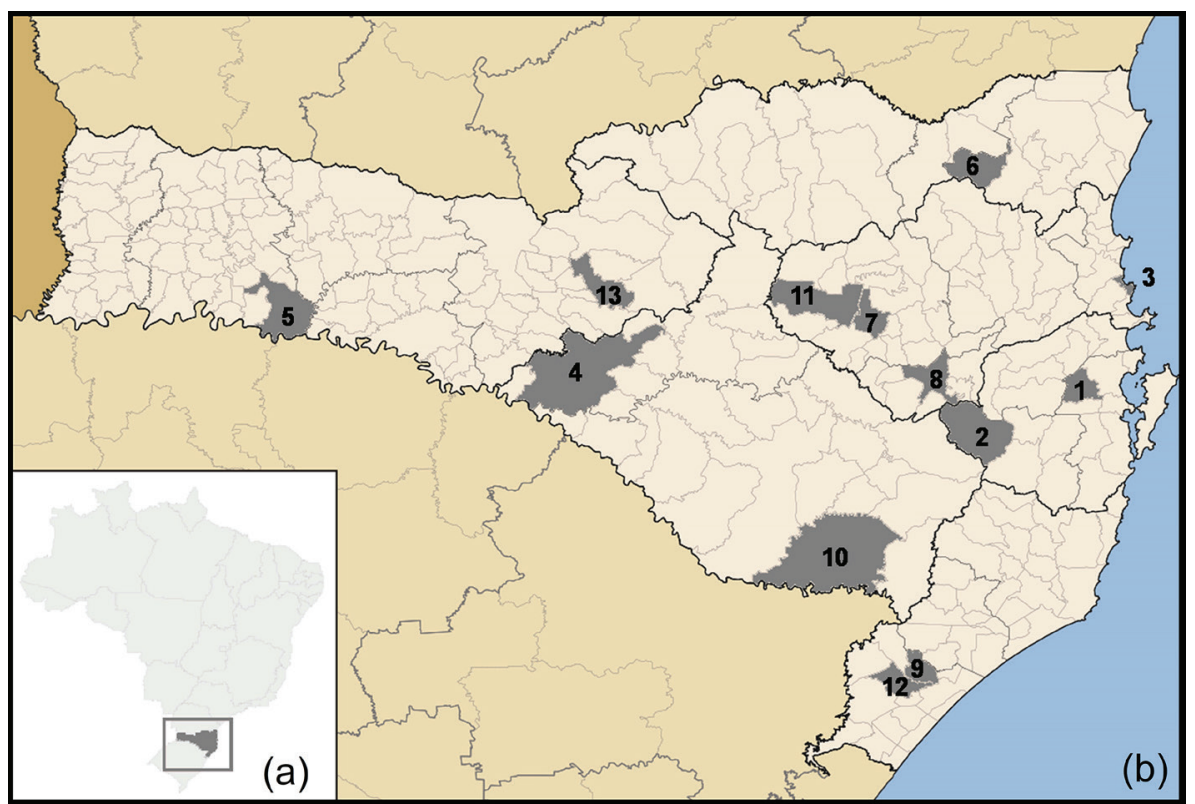

Figure 1. (a) Brazil with Santa Catarina State highlighted and (b) Santa Catarina State showing the municipalities where the water samples were collected (grey highlighting). 1: Antônio Carlos (2 samples); 2: Alfredo Wagner (1 sample); 3: Balneário Camboriú (1 sample); 4: Campos Novos (3 samples); 5: Chapecó (3 samples); 6: Corupá (1 sample); 7: Rio do Oeste (1 sample); 8: Ituporanga (1 sample); 9: Meleiro (1 sample); 10: São Joaquim (1 sample); 11: Taió (2 sample); 12: Turvo (2 samples); 13: Videira (1 sample).

\section{Results and Discussion}

\section{Optimization of DPX procedure}

Selection of the extraction phase and evaluation of sample $\mathrm{pH}$

The pesticides under study exhibit different physicochemical properties, therefore, three DPX sorbent phases with different chemical structures and functional groups were evaluated: $(i)$ DPX-C18, comprised of a carbonic chain with the potential for hydrophobic interactions with the pesticides; (ii) DPX-RP, comprised of styrene-divinylbenzene with the potential for $\pi-\pi$ interactions and hydrophobic interactions with the analytes; ${ }^{19}$ and (iii) DPX-WAX, containing a sorbent phase comprised of poly-amino groups with the potential for hydrogen interactions and hydrophobic interactions with the pesticides. ${ }^{19}$ In addition, the extractions were carried out at different $\mathrm{pH}$ values $(2,4,6,8,10$ and 12). The best extraction of the analytes at $\mathrm{pH} 2$ was obtained using DPX-C18 and DPX-WAX, and at $\mathrm{pH} 4$ using DPX-RP (data not shown). This is possibly due to the fact that most of the analytes are in the neutral form at these $\mathrm{pH}$ values, which increases their interaction with the extraction phase. A comparison of the extraction efficiencies obtained with DPX-C18, DPX-RP and DPX-WAX was performed using the best $\mathrm{pH}$ value for each sorbent phase (Figure 2).

According to the bar graph in Figure 2, the extraction efficiency for DPX-WAX ( $\mathrm{pH}$ 2) was around $40 \%$ higher compared with DPX-RP (pH 4) and DPX-C18 (pH 2). This behavior is due to the structure of this sorbent phase, which contains poly-amino groups that can interact with the analytes through strong hydrogen interactions. Furthermore, hydrophobic interactions may be favored at $\mathrm{pH} 2$ because the analytes are in the neutral form. Based on its better extraction performance, DPX-WAX was characterized by FTIR and SEM to confirm the functional groups and evaluate its morphology.

\section{Characterization of sorbent phase}

The WAX sorbent phase was characterized through FTIR spectroscopy and SEM to elucidate the functional groups and morphology of the sorbent. The FTIR spectrum obtained for this extraction phase is shown in Figure 3.

According to Figure 3, the sorbent phase exhibits an absorption band at $3400 \mathrm{~cm}^{-1}$, characteristic of the stretching of the $\mathrm{N}-\mathrm{H}$ bond of a secondary amine. Bands in the range of 1350 to $1000 \mathrm{~cm}^{-1}$ are related to stretching of the $\mathrm{C}-\mathrm{N}$ bond. The absorption band at $3050 \mathrm{~cm}^{-1}$ is attributed to stretching of the $\mathrm{C}-\mathrm{H}$ bond of unsaturated carbon, possibly at the aromatic ring, and the band at $2850 \mathrm{~cm}^{-1}$ is assigned to stretching of the $\mathrm{C}-\mathrm{H}$ bond of a saturated carbon. The absorption band at $1650 \mathrm{~cm}^{-1}$ can be attributed to ring stretching. In addition, the macrographs obtained by SEM at different magnifications are shown in Figure 4.

According to the SEM images, WAX exhibits a large amount of particles of the same shape but different sizes. These characteristics combined with the fact that WAX is 


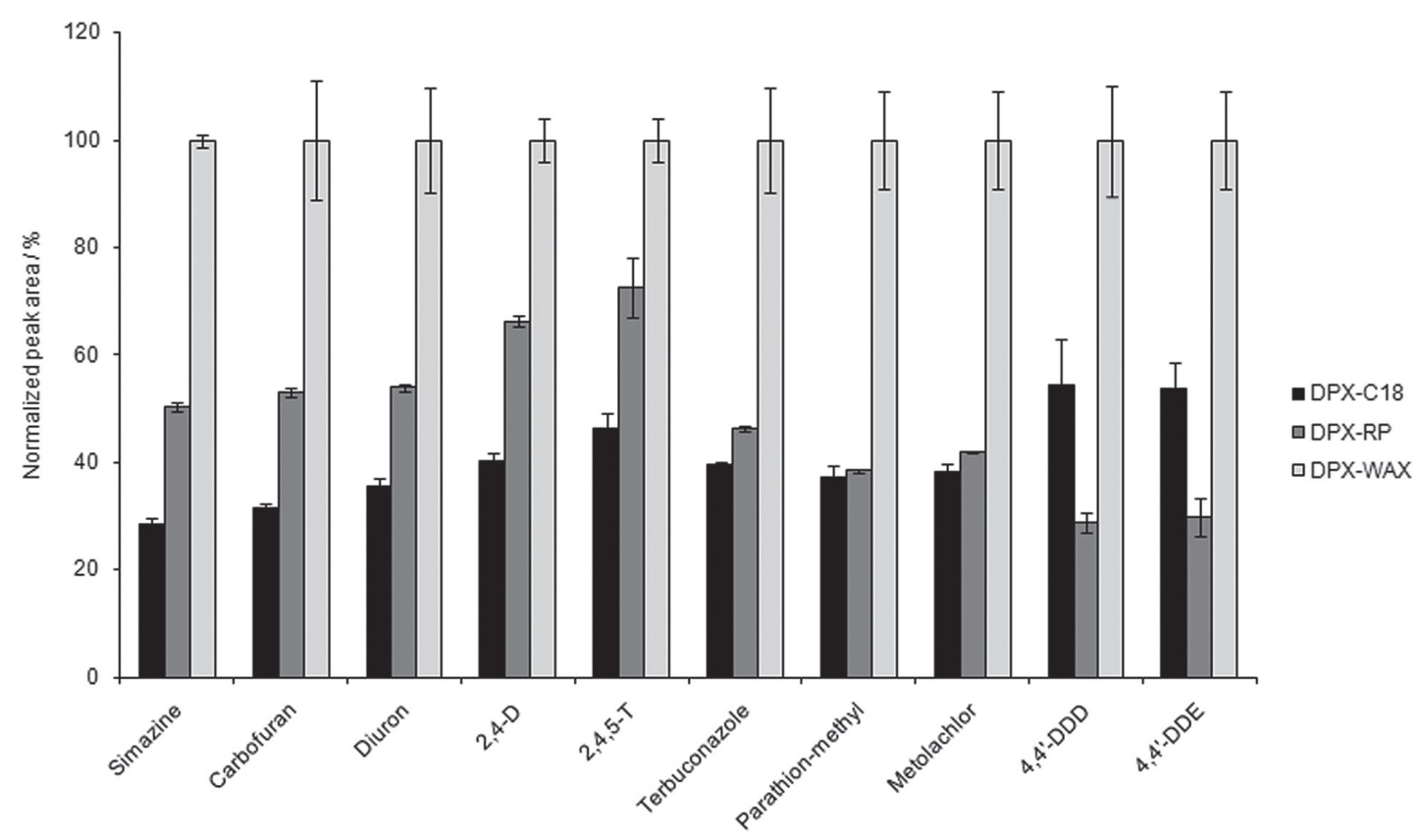

Figure 2. Comparison of the extraction efficiency obtained with DPX-C18, DPX-RP and DPX-WAX. Extraction performed at pH 2 with DPX-C18 and DPX-WAX, and at $\mathrm{pH} 4$ with DPX-RP. The experiments were performed using $500 \mu \mathrm{g} \mathrm{L}^{-1}$ of each analyte, 3 extraction cycles with $700 \mu \mathrm{L}$ of the sample in each cycle and $30 \mathrm{~s}$ of extraction time, 2 cycles of desorption with $200 \mu \mathrm{L}$ of ACN (same aliquot) and $30 \mathrm{~s}$ of desorption time.

a fine powder, which can be well dispersed at the tip when the extraction is performed, with high area of contact

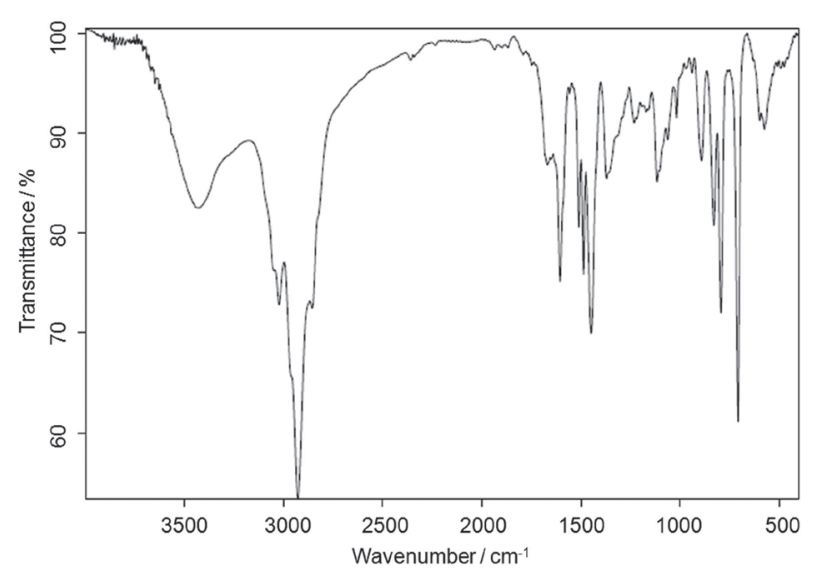

Figure 3. FTIR spectrum of the sorbent phase WAX. between the sample and extraction phase, contribute to the good results obtained with extractions using DPX-WAX. Therefore, DPX-WAX was fully optimized to obtain the best conditions for the extraction of the analytes.

\section{Optimization of the desorption solvent}

The liquid desorption step is an important parameter that needs to be optimized to obtain the complete desorption of the analytes from the sorbent phase $\mathrm{e}^{14}$ and avoid the carryover effect. In this study, $\mathrm{MeOH}, \mathrm{ACN}$ and acetone, along with mixtures of these solvents, were evaluated through a simplex-lattice design. The results obtained are presented as a triangular surface in Figure 5.

As can be seen in Figure 5, when $\mathrm{MeOH}$ and acetone were used the response was not satisfactory. However, when the ratio of ACN was increased the desorption efficiency
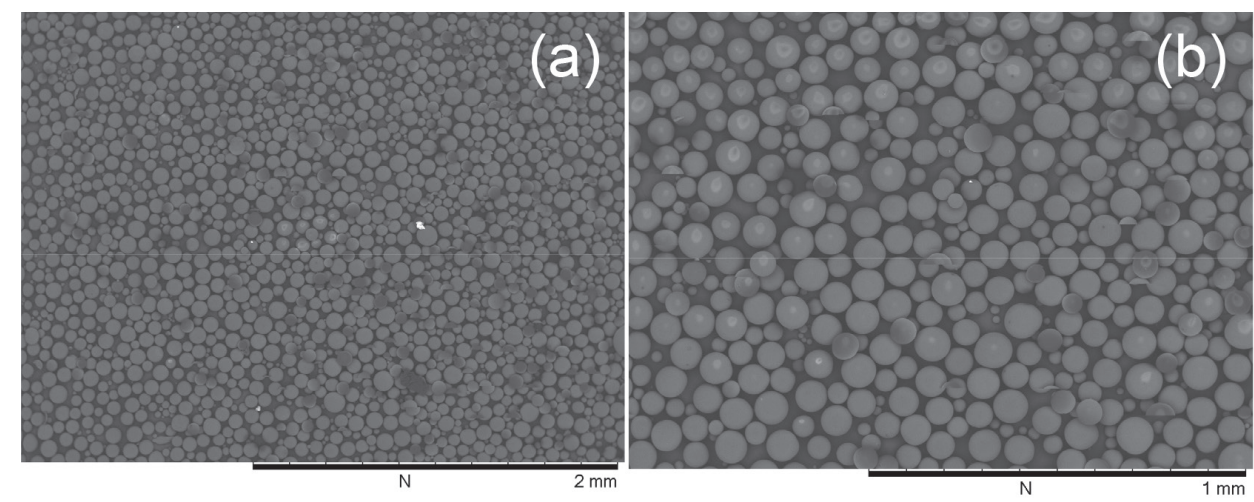

Figure 4. SEM micrographs of the sorbent phase WAX: (a) magnification of 50x and (b) magnification of 100x. 


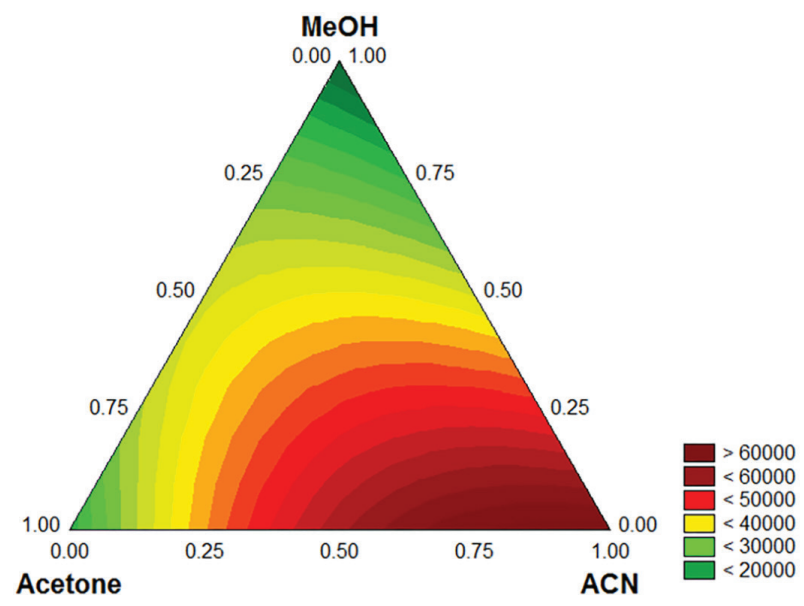

Figure 5. Triangular response surface obtained using geometric means of the analytes in the optimization of the desorption solvent. The experiments were performed using $100 \mu \mathrm{g} \mathrm{L}^{-1}$ of each analyte at $\mathrm{pH} 2,3$ extraction cycles with $700 \mu \mathrm{L}$ of the sample in each cycle and $30 \mathrm{~s}$ of extraction time, 2 desorption cycles with $200 \mu \mathrm{L}$ of solvent (same aliquot) and $30 \mathrm{~s}$ of desorption time.

was enhanced, and the best response for the desorption of the analytes was achieved using $100 \%$ of ACN. Thus, this condition was adopted for further experiments.

\section{Optimization of extraction and desorption steps}

In the DPX procedure it is important to optimize the conditions for the extraction and desorption steps. The

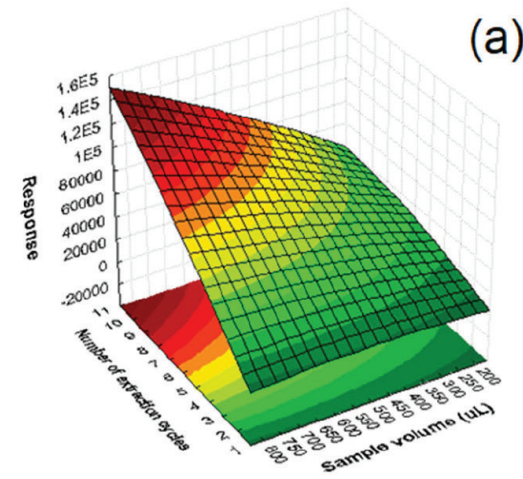

(a)

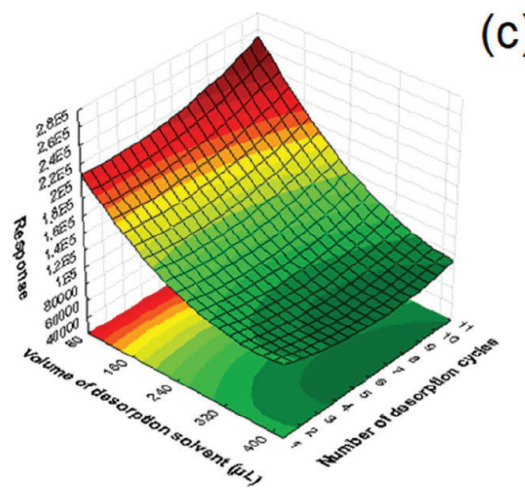

(c)
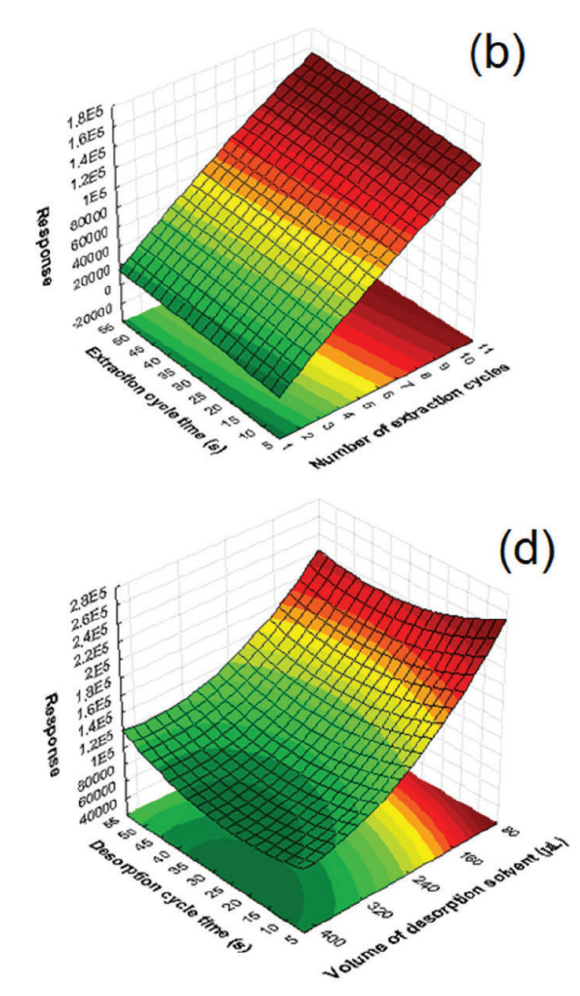

parameters evaluated in the extraction step were sample volume (165 to $835 \mu \mathrm{L}$ ), number of extraction cycles ( 1 to 11 ) and time of each cycle ( 5 to $55 \mathrm{~s}$ ). With respect to the desorption step, the parameters evaluated were the volume of desorption solvent ( 80 to $420 \mu \mathrm{L}$ ), number of desorption cycles ( 1 to 11 ) and time of each cycle ( 5 to $55 \mathrm{~s}$ ). ${ }^{15,20}$ These variables were investigated based on a central composite design. The graphics generated using the geometric means of the chromatographic peak areas for the analytes are shown in Figures 6a-6d.

According to Figure 6a, it can be observed that increasing the sample volume the chromatographic responses for the analytes also increased. In addition, the chromatographic response was enhanced by increasing the number of extraction cycles. This is because of the aspiration of a new sample aliquot in each extraction cycle. However, the chromatographic peak areas of the analytes were similar using 8 and 11 cycles. Therefore, 8 extraction cycles was the number selected to increase the analysis throughput. In Figure $6 \mathrm{~b}$, it can be observed that the extraction time does not influence the chromatography responses and $15 \mathrm{~s}$ was adopted as the time for each extraction cycle. Therefore, the optimized extraction conditions were comprised of 8 extraction cycles of $15 \mathrm{~s}$ each using $800 \mu \mathrm{L}$ of a new aliquot of sample in each cycle. These conditions were applied in the subsequent experiments.

Figure 6. Optimization of the extraction and desorption conditions through a central composite design. Response surfaces shown in (a) and (b) represent the optimization of the extraction step; (c) and (d) represent the optimization of the desorption step. The experiments were performed using $100 \mu \mathrm{g} \mathrm{L}^{-1}$ of each analyte, $\mathrm{pH} 2, \mathrm{ACN}$ for the desorption, and $0 \%$ of $\mathrm{NaCl}$. 
In the desorption step, according to Figure 6c, the best performance was obtained with lower volumes of ACN, which can be explained by the higher concentration of analytes. Thus, $100 \mu \mathrm{L}$ of ACN were chosen as an optimized desorption condition. In addition, it can be observed that 7 cycles provide adequate desorption of the analytes, in this case, the same aliquot of ACN was used sequentially to improve the desorption and ensure no carryover effect. It can be noted from Figure $6 \mathrm{~d}$ that the desorption time does not influence the chromatographic response. In summary, the optimized desorption conditions were comprised of 7 cycles of desorption of $15 \mathrm{~s}$ each using the same aliquot of ACN $(100 \mu \mathrm{L})$. These conditions were applied in the subsequent experiments.

\section{Optimization of $\mathrm{NaCl}$ concentration added to the sample}

In some cases, the addition of salt to aqueous samples can improve the extraction efficiency of the organic compounds by reducing the solubility of these compounds in the aqueous phase. This phenomenon is known as the salting out effect and it is observed mainly for medium to high polarity compounds. ${ }^{21,22}$ In this study, this parameter was evaluated in the univariate mode and extractions were performed without the addition of $\mathrm{NaCl}$ and with the addition of 15 and $30 \% \mathrm{~m} / \mathrm{v}$ of $\mathrm{NaCl}$ in aqueous samples containing the analytes. The normalized chromatographic peak areas obtained for the analytes were considered and the results are shown in Figure 7.

According to the bar graph in Figure 7, satisfactory results were obtained with the addition of $15 \% \mathrm{~m} / \mathrm{v}$ of $\mathrm{NaCl}$, even for the most nonpolar compounds. The addition of $30 \% \mathrm{~m} / \mathrm{v} \mathrm{NaCl}$ did not enhance the extraction of the analytes. This was because the precipitation of some of the $\mathrm{NaCl}$ occurred in organic medium when high salt concentrations were used, leading to the formation of particles that can block the active sites of the extraction phase. Therefore, $15 \% \mathrm{~m} / \mathrm{v}$ of $\mathrm{NaCl}$ was chosen as the best condition for the extraction of the pesticides under study.

After all optimization steps had been completed, the ideal extraction conditions were fixed as: use of WAX as the sorbent phase in DPX procedure, sample $\mathrm{pH}$ 2, 8 extraction cycles using $800 \mu \mathrm{L}$ of a new aliquot of sample and $15 \mathrm{~s}$ for each extraction cycle, and addition of $15 \% \mathrm{~m} / \mathrm{v}$ of $\mathrm{NaCl}$ in the samples. With regard to the desorption step, the optimized conditions were comprised of 7 desorption cycles using $100 \mu \mathrm{L}$ of $\mathrm{ACN}$ and $15 \mathrm{~s}$ for each cycle. After this full optimization, the optimized conditions were adopted to determine the analytical parameters of merit of the proposed methodology.

Determination of the analytical parameters of merit and analysis of water samples

The calibration was conducted using tap water samples spiked with the pesticides at different concentrations. The extractions were performed under the conditions previously optimized for DPX-WAX. The linear equation, linear range, r, LOD and LOQ are shown in Table 2.

The correlation coefficients ranged from 0.9923 for 4,4'-DDE to 0.9999 for simazine, which indicates good linear correlations for the data. In addition, the linearity of the calibration curves was verified using ANOVA, and the

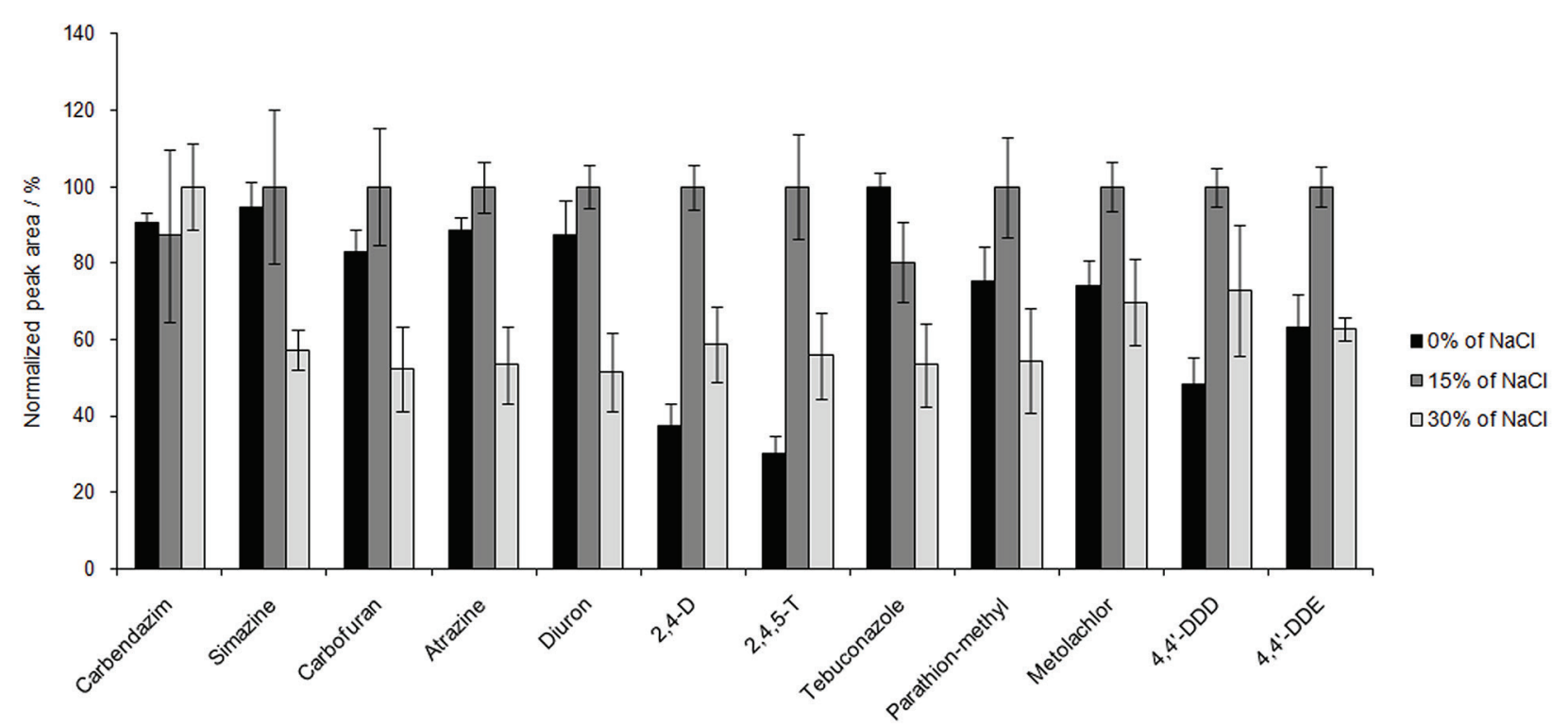

Figure 7. Evaluation of $\mathrm{NaCl}$ percentage added to the sample. Extraction performed without $\mathrm{NaCl}$, and with 15 and $30 \%$ of $\mathrm{NaCl}$ in the sample solution. Other experimental conditions were: $100 \mu \mathrm{g} \mathrm{L}{ }^{-1}$ of each analyte, $\mathrm{pH}$ 2, 8 extraction cycles with $800 \mu \mathrm{L}$ of sample in each cycle and $15 \mathrm{~s}$ of extraction time, 7 desorption cycles with $100 \mu \mathrm{L}$ of $\mathrm{ACN}$ (same aliquot) and $15 \mathrm{~s}$ of desorption time. 
Table 2. Analytical parameters of merit of the method proposed using DPX-WAX

\begin{tabular}{|c|c|c|c|c|c|}
\hline Analyte & Linear equation & Linear range / $\left(\mu \mathrm{g} \mathrm{L}^{-1}\right)$ & $\mathrm{r}$ & $\mathrm{LOD} /\left(\mu \mathrm{g} \mathrm{L}^{-1}\right)$ & $\mathrm{LOQ} /\left(\mu \mathrm{g} \mathrm{L}^{-1}\right)$ \\
\hline Carbendazim & $y=57889 x+5951.5$ & $50-600$ & 0.9967 & 0.69 & 2.30 \\
\hline Simazine & $y=3827.8 x+1102.3$ & $1-200$ & 0.9999 & 0.07 & 0.22 \\
\hline Carbofuran & $y=7011.8 x+37813$ & $5-200$ & 0.9997 & 0.02 & 0.06 \\
\hline Atrazine & $y=3352.1 x-185.29$ & $5-200$ & 0.9995 & 0.11 & 0.37 \\
\hline Diuron & $y=3216.1 x+838.41$ & $1-200$ & 0.9995 & 0.06 & 0.18 \\
\hline 2,4-D & $y=5427.7 x+8755.4$ & $5-200$ & 0.9991 & 0.04 & 0.14 \\
\hline $2,4,5-\mathrm{T}$ & $y=4523.5 x+4634.4$ & $5-200$ & 0.9993 & 0.05 & 0.17 \\
\hline Tebuconazole & $y=2722.9 x-4761.9$ & $5-200$ & 0.9998 & 0.18 & 0.59 \\
\hline Parathion-methyl & $y=1792.1 x+17805$ & $5-200$ & 0.9996 & 0.13 & 0.42 \\
\hline Metolachlor & $y=3435.1 x+1359.7$ & $5-200$ & 0.9994 & 0.11 & 0.37 \\
\hline 4,4'-DDD & $y=1056.7 x+9391.1$ & $5-200$ & 0.9930 & 0.13 & 0.43 \\
\hline 4,4'-DDE & $y=507.81 x+4462$ & $5-200$ & 0.9923 & 0.24 & 0.79 \\
\hline
\end{tabular}

r: correlation coefficient; LOD: limit of detection; LOQ: limit of quantification; 2,4-D: 2,4-dichlorophenoxy acetic acid; 2,4,5-T: 2,4,5-trichlorophenoxy acetic acid; 4,4'-DDD: dichlorodiphenyldichloroethane; 4,4'-DDE: dichlorodiphenyldichloroethylene.

data are shown in Table S1 (Supplementary Information (SI) section). All of the calibration curves exhibited very small values for significance $(\mathrm{F})$, providing strong evidence of correlations between the dependent and independent variables. In addition, there was a good linear relationship, since the mean square due to regression is much greater than the residual mean square. Satisfactory LOQ values were obtained, ranging from 0.06 to $2.30 \mu \mathrm{g} \mathrm{L} \mathrm{L}^{-1}$ for carbofuran and carbendazim, respectively. On comparing the LOQs with the maximum concentration levels (MCLs) for pesticides based on Brazilian legislation, ${ }^{4}$ it can be observed that LOQs lower than the MCLs were obtained for all analytes.

The recovery assays were used to evaluate the accuracy of the method by spiking tap water samples with three concentrations of the analytes. The precision of the method was evaluated by intraday and interday assays, also at three concentrations. The values for the relative recovery and precision are shown in Table 3.

Based on the results in Table 3, the method achieved satisfactory relative recoveries for all pesticides (75 to $117 \%)$. The intraday precision $(n=3)$ was also adequate, varying from 1 to $20 \%$ for all pesticides, and the interday precision $(n=9)$ ranged from 1 to $24 \%$. These results adhere to the validation guidelines for pesticide residue analysis. ${ }^{23}$

In addition, the robustness of the method was evaluated through the Youden test. In this case, some modifications to the DPX procedure were adopted as follows: $\mathrm{P} 1$ corresponding to the concentration of $\mathrm{NaCl}$ $($ nominal $=15 \%$, variation $=18 \%) ; \mathrm{P} 2$ corresponding to the number of extraction cycles (nominal $=8$ cycles, variation $=7$ cycles); P3 corresponding to the number of desorption cycles (nominal $=7$, variation $=6$ cycles); $\mathrm{P} 4$ corresponding to the sample $\mathrm{pH}$ (nominal $=2$, variation $=2.5$ ); P5 corresponding to the volume of $\mathrm{ACN}$ used for the desorption (nominal $=100 \mu \mathrm{L}$, variation $=120 \mu \mathrm{L}$ ) and P6 corresponding to the sample volume (nominal $=800 \mu \mathrm{L}$, variation $=780 \mu \mathrm{L}$ ). The results are shown in Figure S1 (SI section), with data expressed in Lenth (Figure S1a) and Daniel (Figure S1b) graphs. According to Figures S1a and S1b, the slight changes in the extraction parameters did not influence the overall results for the extraction of the pesticides under study. Therefore, the proposed method exhibited adequate robustness and it is suitable for application to real samples.

A chromatogram obtained from a tap water sample spiked with $200 \mu \mathrm{g} \mathrm{L}^{-1}$ of each pesticide using the optimized conditions is shown in Figure S2 (SI section). According to the chromatogram, good separation was obtained for the analytes, with well-resolved peaks without coelutions. The fully optimized DPX-WAX procedure was efficient for the removal of interfering compounds and for the concentration of the analytes, since no peaks were observed at the same retention time of the analytes and the method provided satisfactory detectability for the compounds under study.

In order to evaluate the quality of water, which is effectively provided to the population, after obtaining the analytical parameters of merit, water samples were collected from water treatment plants located in 13 cities of Santa Catarina State, Brazil, totaling 20 samples. On applying the method developed, the analytes under study were not detected in these samples. These results indicate that the water used for human consumption in these regions 
Table 3. Relative recovery and intra/interday precision for the pesticides under study

\begin{tabular}{|c|c|c|c|c|}
\hline \multirow[b]{2}{*}{ Analyte } & \multirow{2}{*}{$\begin{array}{c}\text { Spiked } \\
\text { concentration / } \\
\left(\mu \mathrm{g} \mathrm{L}^{-1}\right)\end{array}$} & \multirow{2}{*}{$\begin{array}{c}\text { Relative } \\
\text { recovery / \% } \\
(\mathrm{n}=3)\end{array}$} & \multicolumn{2}{|c|}{ Precision (RSD / \%) } \\
\hline & & & $\begin{array}{c}\text { Intraday } \\
(\mathrm{n}=3)\end{array}$ & $\begin{array}{c}\text { Interday } \\
(\mathrm{n}=9)\end{array}$ \\
\hline \multirow{3}{*}{ Carbendazim } & 50 & 86 & 20 & 21 \\
\hline & 200 & 111 & 4 & 14 \\
\hline & 600 & 75 & 19 & 24 \\
\hline \multirow{3}{*}{ Simazine } & 1 & 91 & 18 & 5 \\
\hline & 50 & 115 & 11 & 2 \\
\hline & 200 & 101 & 7 & 3 \\
\hline \multirow{3}{*}{ Carbofuran } & 5 & 104 & 7 & 7 \\
\hline & 50 & 113 & 11 & 2 \\
\hline & 200 & 100 & 7 & 2 \\
\hline \multirow{3}{*}{ Atrazine } & 5 & 99 & 5 & 11 \\
\hline & 50 & 112 & 11 & 4 \\
\hline & 200 & 100 & 8 & 3 \\
\hline \multirow{3}{*}{ Diuron } & 1 & 103 & 11 & 1 \\
\hline & 50 & 110 & 11 & 17 \\
\hline & 200 & 100 & 8 & 10 \\
\hline \multirow{3}{*}{$2,4-\mathrm{D}$} & 5 & 89 & 15 & 11 \\
\hline & 50 & 106 & 10 & 8 \\
\hline & 200 & 97 & 8 & 2 \\
\hline \multirow{3}{*}{$2,4,5-\mathrm{T}$} & 5 & 89 & 12 & 12 \\
\hline & 50 & 102 & 10 & 5 \\
\hline & 200 & 95 & 9 & 2 \\
\hline \multirow{3}{*}{ Tebuconazole } & 5 & 85 & 16 & 15 \\
\hline & 50 & 108 & 12 & 4 \\
\hline & 200 & 99 & 10 & 3 \\
\hline \multirow{3}{*}{ Parathion-methyl } & 5 & 92 & 8 & 15 \\
\hline & 50 & 105 & 11 & 1 \\
\hline & 200 & 101 & 9 & 14 \\
\hline \multirow{3}{*}{ Metolachlor } & 5 & 92 & 9 & 14 \\
\hline & 50 & 107 & 12 & 11 \\
\hline & 200 & 99 & 9 & 3 \\
\hline \multirow{3}{*}{ 4,4'-DDD } & 5 & 93 & 8 & 11 \\
\hline & 50 & 109 & 10 & 11 \\
\hline & 200 & 107 & 6 & 5 \\
\hline \multirow{3}{*}{ 4,4'-DDE } & 5 & 101 & 1 & 10 \\
\hline & 50 & 117 & 13 & 7 \\
\hline & 200 & 114 & 4 & 6 \\
\hline
\end{tabular}

RSD: relative standard deviation; 2,4-D: 2,4-dichlorophenoxy acetic acid; 2,4,5-T: 2,4,5-trichlorophenoxy acetic acid; 4,4'-DDD: dichlorodiphenyldichloroethane; 4,4'-DDE: dichlorodiphenyldichloroethylene.

of Santa Catarina State is of good quality and verifies the efficiency of the water treatment plants.

\section{Conclusions}

The method developed using DPX-WAX as a sample preparation technique and HPLC-DAD for the separation/ determination of pesticides in drinking water samples was efficient for the determination of all analytes studied, since the LOQs were smaller than the MCLs established by Brazilian regulations. In this study, the DPX-WAX was successfully exploited as a sample preparation procedure and exhibited important features including satisfactory analyte concentration, low-cost and high-throughput analysis. In addition, the DPX-WAX procedure is simple and easy to perform, the extractions can be carried out in a few seconds, and the configuration can be automated. The method can be conducted with a small volume of organic solvent $(100 \mu \mathrm{L})$ and low extraction phase mass (20 mg), and thus adheres to green chemistry principles. The analytes studied were not detected in the 20 samples collected, demonstrating the satisfactory quality of the drinking water available in some regions of Santa Catarina State.

\section{Supplementary Information}

Supplementary data are available free of charge at http://jbcs.sbq.org.br as PDF file.

\section{Acknowledgments}

This work was financially supported by Fundação de Amparo à Pesquisa e Inovação do Estado de Santa Catarina (FAPESC) process number 455/2016, Conselho Nacional de Desenvolvimento Científico e Tecnológico (CNPq) process number 303892/2014-5, Coordenação de Aperfeiçoamento de Pessoal de Nível Superior (CAPES) finance code 001 and Universidade Federal de Santa Catarina (UFSC). In addition, the authors acknowledge the Central de Análises of UFSC for the FTIR analysis and Vigilância Sanitária do Estado de Santa Catarina for collection of the water samples.

\section{References}

1. Gonzalez-Curbelo, M. A.; Herrera-Herrera, A. V.; HernandezBorges, J.; Rodriguez-Delgado, M. A.; J. Sep. Sci. 2013, 36, 556.

2. Giordano, G.; Afsharinejad, Z.; Guizzetti, M.; Vitalone, A.; Kavanagh, T. J.; Costa, L. G.; Toxicol. Appl. Pharmacol. 2007, $219,181$.

3. Rigotto, R. M.; Vasconcelos, D. P.; Rocha, M. M.; Cad. Saude Publica 2014, 30, 1360.

4. Ministério da Saúde; Portaria No. 2.914 de 12 de dezembro de 2011 Dispõe sobre os Procedimentos de Controle e de Vigilância da Qualidade da Água para Consumo Humano e seu Padrão de Potabilidade; Ministério da Saúde: Brasília, 2011. Available at http://bvsms.saude.gov.br/bvs/saudelegis/gm/2011/ prt2914_12_12_2011.html, accessed in January 2019. 
5. Tankiewicz, M.; Biziuk, M.; Anal. Bioanal. Chem. 2018, 410, 1533.

6. Jones, L.; Kinsella, B.; Forde, K.; Furey, A.; Regan, F.; Anal. Methods 2017, 9, 4167.

7. Donato, F. F.; Bandeira, N. M. G.; dos Santos, G. C.; Prestes, O. D.; Adaime, M. B.; Zanella, R.; J. Chromatogr. A 2017, 1516, 54.

8. Valls-Cantenys, C.; Scheurer, M.; Iglesias, M.; Sacher, F.; Brauch, H. J.; Salvado, V.; Anal. Bioanal. Chem. 2016, 408, 6189.

9. do Carmo, S. N.; Merib, J.; Dias, A. N.; Stolberg, J.; Budziak, D.; Carasek, E.; J. Chromatogr. A 2017, 1525, 23.

10. Martins, M. L.; Prestes, O. D.; Adaime, M. B.; Zanella, R.; Anal. Methods 2014, 6, 5020.

11. dos Anjos, J. P.; de Andrade, J. B.; Microchem. J. 2014, 112, 119.

12. Gonzalez-Curbelo, M. A.; Socas-Rodriguez, B.; HerreraHerrera, A. V.; Gonzalez-Salamo, J.; Hernandez-Borges, J.; Rodriguez-Delgado, M. A.; TrAC, Trends Anal. Chem. 2015, $71,169$.

13. Brewer, W.; US pat. 6,566,145 B2, 2003.

14. Bordin, D. C. M.; Alves, M. N. R.; de Campos, E. G.; de Martinis, B. S.; J. Sep. Sci. 2016, 39, 1168.

15. Corazza, G.; Merib, J.; Magosso, H. A.; Bittencourt, O. R.; Carasek, E.; J. Chromatogr. A 2017, 1513, 42.
16. ChemAxon Ltd.; Chemicalize, Instant Cheminformatics Solutions; ChemAxon Ltd., Hungary, 2017. Available at https:// chemicalize.com/welcome, accessed in January 2017.

17. StatSoft, Inc.; Statistica, version 8.0; StatSoft, Inc., USA, 2007.

18. Estatcamp and DigUp; Action Start software, version 3.5.152.34 build 4; Universidade de Campinas, Brazil, 2018.

19. http://dpxtechnologies.com/, accessed in January 2019.

20. Borges, K. B.; Figueiredo, E. C.; Queiroz, M. E. C.; Preparo de Amostras para Análise de Compostos Orgânicos; LTC: Rio de Janeiro, 2015.

21. Kokosa, J. M.; Przyjazny, A.; Jeannot, M. A.; Solvent Microextraction: Theory and Practice; John Wiley \& Sons, Hoboken, 2009.

22. Psillakis, E.; Kalogerakis, N.; TrAC, Trends Anal. Chem. 2003, 22, 565 .

23. European Commission (EC), Directorate-General for Health and Food Safety; Guidance Document on Analytical Quality Control and Method Validation Procedures for Pesticides Residues Analysis in Food and Feed, SANTE 11945/2015; EC: Brussels, 2015.
Submitted: October 19, 2018

Published online: February 4, 2019 